\title{
EPISTEMIC VIGILANCE, CAUTIOUS OPTIMISM AND SOPHISTICATED UNDERSTANDING
}

\author{
ManUel Padilla CRUZ \\ University of Seville \\ mpadillacruz@us.es
}

\begin{abstract}
Humans have developed a critical alertness to the believability and reliability of communication: epistemic vigilance (Sperber et al. 2010). It is responsible for trusting interlocutors and believing interpretations. But what is exactly its role in communication? This paper suggests that epistemic vigilance may trigger shifts from a default processing strategy driven by expectations of optimal relevance to more complex processing strategies. These would be enacted when hearers notice speakers' linguistic mistakes, hearers realise that they have made interpretive mistakes or when hearers discover that speakers seek to mislead them to erroneous or unintended interpretations.
\end{abstract}

\section{Introduction}

Relevance Theory (Sperber and Wilson 1986, 1995; Wilson and Sperber $2002,2004)$ puts forward a model of utterance interpretation in which the comprehension module performs several simultaneous tasks. Their result is an interpretation of the utterance, which, if considered to be optimally relevant, will be regarded as the speaker's informative intention - i.e. the set of assumptions that she intends to make manifest or, in other terms, what she purports to communicate. But in order to think that a particular interpretation is what the speaker intends to communicate, hearers must believe speakers are willing to do so and trust them as both information givers and competent, skilful communicators who make use of the linguistic code in an efficient way. Also, hearers must trust and rely on their own interpretive abilities and capabilities, as they may make interpretive mistakes that might go unnoticed.

When communicating we exchange information that may be true, false, incomplete, ambiguous, tricky, deceptive or presented to us not in the best linguistic form. Humans have developed complex cognitive 
mechanisms targeted at their sources of information and the content of information that they process. These check speakers' competence and benevolence and the credibility of information. Mascaro and Sperber (2009) and Sperber et al. (2010) argue that such mechanisms make up a mental module, which they label epistemic vigilance. This module is, therefore, responsible for one of the perlocutionary effects of communication, namely, whether we end up believing our interlocutors and the information they provide us with (Sperber et al. 2010; Wilson 2011, 2012a, 2012b). It checks both the quality of the information we receive and the individuals who dispense it. As a mental module, it has a very specific domain of operation and works in an incredibly fast and subconscious way. However, if it contributes to the mentioned perlocutionary effect and hence plays a crucial role in communication, it might somehow be related to the comprehension module and affect its tasks.

This paper suggests what that relation between epistemic vigilance and the comprehension module might be and the consequences of its working on the comprehension module. It argues that, as a verifier of the reliability and credibility of both communicators and information exchanged, epistemic vigilance checks, on the one hand, our interlocutors' benevolence and linguistic or pragmatic competence, and, on the other hand, it monitors and surveys the different interpretive steps that we take as hearers, their potential or actual outcomes and the pragmatic material exploited in them in order to test their trustworthiness, usefulness and viability for the process of comprehension. If it discovers that something goes wrong or might go wrong, it is capable of instructing the comprehension module to adopt more complex and effort-demanding processing strategies than the strategy that it might make use of by default, driven by expectations and considerations of optimal relevance. More specifically, this paper proposes that epistemic vigilance is able to make the comprehension module shift from the strategy labelled naïve optimism to either cautious optimism or sophisticated understanding (Sperber 1994). Such shifts would be enacted if epistemic vigilance discovers that (i) our interlocutors are not (very) competent language users, (ii) we make interpretive mistakes at either the explicit or implicit level of communication, and (iii) our interlocutors either do not behave benevolently and intentionally try to deceive us by offering information that cannot or should not be believed or play with us by inducing us to arrive at an interpretation that could be initially accepted and believed, but must be subsequently rejected. In other words, epistemic vigilance might trigger the said processing strategies when it finds out that speakers make expressive mistakes, we make interpretive mistakes or speakers 
intentionally mislead us or playfully fool us for the sake of achieving effects like humour.

This paper is organised as follows. Section 2 briefly summarises some of the relevance-theoretic postulates on and claims about utterance interpretation and introduces epistemic vigilance. Section 3 describes naïve optimism and argues that it may be the processing strategy that the comprehension module resorts to by default. Then, Section 4 shows that naïve optimism may be abandoned in favour of cautious optimism when epistemic vigilance notices that either the speaker may not have a proper command of language or that the comprehension module may be affected by temporary or permanent pragmatic deficits. Finally, Section 5 argues that the comprehension module may turn to sophisticated understanding when epistemic vigilance detects that the speaker is trying to fool and mislead the hearer to an interpretation that does not correspond to her actual informative intention. It illustrates this by discussing how epistemic vigilance would react to a playful, innocuous, amicable type of deception like jokes.

\section{Relevance and epistemic vigilance in comprehension}

Relevance Theory (Sperber and Wilson 1986, 1995; Wilson and Sperber 2002,2004 ) is grounded on two general principles based on a tendency of our cognitive mechanism, which seem to be the result of centuries of continuous evolution in order to achieve greater efficiency of resources. On the one hand, the Cognitive Principle of Relevance states that "Human cognition tends to be geared to the maximisation of relevance". On the other hand, the Communicative Principle of Relevance claims that "Every act of ostensive communication communicates a presumption of its own optimal relevance" (Sperber and Wilson 1995: 260).

Relevance theory seeks to solve the problem of why, out of the many possible interpretations that utterances and stretches of discourse may have, all of them compatible with the information linguistically encoded, hearers arrive at one interpretation. It argues that comprehension is relevance-driven and that hearers opt for one particular interpretation and believe it to be the speaker's informative intention on the basis of the expectations of relevance that utterances generate. It defines relevance as a feature of ostensive stimuli like utterances which depends on two factors:

a) The cognitive effort that the hearer will have to invest when processing an utterance. This depends on the psychological 
complexity of utterances or the mental effort required in selecting an appropriate context for interpretation.

b) The cognitive effects that the processing of the utterance will yield. These are the benefits the utterance will provide the hearer with, i.e. strengthening of previous information, contradiction and rejection of old information, or the derivation of new information from the information the utterance makes manifest and the old information the hearer has stored -contextual implications.

Expectations of relevance are constant throughout the comprehension process, which involve both decoding and inference. The former is performed by the language module of the brain and its output is a logical form, or structured sequence of concepts parsed and grouped into sentential constituents (Sperber and Wilson 1995: 74). But the logical form of an utterance is not fully propositional and hence communicatively useless unless it is pragmatically enriched with contextual information. Such process involves the assignment of reference to certain expressions, the disambiguation of syntactic material, the narrowing or broadening of concepts up to a point in which $a d-h o c$, occasion-specific concepts are built, and free enrichment of non-coded concepts (Carston 2002, 2010).

The result of these tasks is a fully-fledged propositional form, or the basic explicature of the utterance. This may be further inserted into a speech-act or propositional-attitude description. If this basic explicature is a lower-level explicature of an utterance, such a description is its higherlevel explicature. The explicature of an utterance may be what the speaker intends to communicate in an explicit way. However, if the hearer has evidence to believe or senses that the speaker might intend to communicate some message implicitly, his expectations of relevance will prompt him to use the explicature as further input for inferential processes with a view to arriving at that implicit content. Then, the hearer will relate it to any other contextual assumptions manifest to him which he feels the speaker intended him to use -implicated premises- in order to reach the implicated conclusion that she wanted to communicate. Those assumptions make up the context for interpretation and are stored in an organised way. Some of them are cultural information or cultural metarepresentations (Sperber 1996), while others are grouped in different types of make-sense frames (Yus Ramos, forthcoming a), schemata or 
scripts in order to capture different aspects of reality, experience, relations etc $^{1}$.

All these interpretive processes are not sequential, but happen simultaneously. When carrying them out, hearers normally follow the path requiring the least cognitive effort possible and yielding the highest amount of cognitive benefit. This tendency is known as the relevancetheoretic comprehension procedure, and entitles hearers to allocate the minimum processing effort possible when constructing interpretive hypotheses about both the explicit and implicit content of utterances and to stop processing when their expectations of relevance are satisfied, i.e. when they feel that they have obtained some worthy cognitive gain. If the interpretation at which they stop is the least effort-requiring and the most effect-yielding one, that interpretation will be optimally relevant. Since comprehension is relevance-driven, once the comprehension module finds an optimally relevant interpretation, the hearer may conclude that such interpretation corresponds to what the speaker intended to communicate.

However, for the hearer to conclude and believe that an optimally relevant interpretation may in fact be what the speaker intended to communicate and expected him to arrive at, the hearer must trust his information sources, i.e. both his interlocutor and the different contextual sources he accesses -cultural metarepresentations, make-sense frames, the physical environment, etc. (Yus Ramos 2000)- and rely on the interpretive procedures conducive to that interpretation. Although the hearer arrives at a particular interpretation and finds it optimally relevant, he might realise that such interpretation was unintended because the speaker made some expressive mistake $-\mathrm{a}$ slip of the tongue, a pragmalinguistic or a sociopragmatic failure (Thomas 1983) - owing to some temporary or constant pragmatic deficit. Alternatively, the hearer may be uncertain about the plausibility of a particular interpretation because he might have made a mistake at any of those steps and consequently feel that, to a greater or lesser extent, he has misunderstood his interlocutor. Therefore, he must make sure that the different interpretive steps he takes and their outcomes are fool-proof.

Our cognitive mechanism seems to have developed a certain capacity to check whether we can trust and rely on our interlocutors, different information sources and mental procedures. Also the result of evolution

\footnotetext{
1 Yus Ramos (forthcoming a) coins the term make-sense frame in order to overcome the existing overlapping between terms like 'frame', 'schema' and 'script'. Make-sense frames consist of encyclopaedic information related to specific terms (word-associated schemas), actions (sequence-associated scripts) and situations (situation-associated frames).
} 
and the constant search for maximum efficiency, this capacity is epistemic vigilance (Mascaro and Sperber 2009; Sperber et al. 2010). It consists of a captious alertness to the believability and reliability of communication and the individuals involved in it, which incites hearers to adopt a critical stance towards messages, their senders and how they interpret messages (Sperber et al. 2010: 363). As a mental module, it targets and operates on the domain of the information exchanged in communication, the information used in comprehension and the mental operations performed when processing it. Epistemic vigilance does not oppose to trusting, neither is it some kind of default distrust; it is opposed to blind and naïve trust (Sperber et al. 2010). Therefore, it induces individuals to adopt some form of caption towards others, messages, our own abilities and preferences as interpreters and the interpretations we may reach (Padilla Cruz, in press).

Since epistemic vigilance checks the credibility of information and our interlocutors' honesty, it plays a major role in argumentation by testing the internal consistency of assertions and their logical or evidential relations to the contextual information employed to support or disconfirm them (Oswald 2011). Epistemic vigilance mechanisms are also linked to the modality and evidentiality markers that some languages have developed, which activate mental procedures geared to assessing the reliability, honesty and trustworthiness of our communicators and the information that they provide (Unger 2012; Wilson 2012b). As a consequence of its operation, epistemic vigilance may also be crucial in the avoidance of the epistemic injustices that may arise as a result of our interlocutors' perceived temporary or recurrent pragmatic incompetence (Padilla Cruz, forthcoming). If epistemic vigilance evaluates the reliability of information, it may also be postulated to act like some kind of everworking filter or fault-finding checker of interpretations of any information at every step of comprehension: hypotheses about explicatures, implicated premises needed and implicated conclusions expected or intended. If an interpretation passes through the filters of epistemic vigilance and is found to be believable, reasonable and faultfree, the hearer may take it to be the speaker's informative intention, but, more importantly, he may add up the information that it makes manifest to his personal universe of beliefs (Wilson 2011, 2012a, 2012b).

But what happens if an interpretation does not pass the filters of epistemic vigilance? In other words, what if epistemic vigilance does not find the speaker to be (fully) competent or trustworthy, or, alternatively, if it detects that something could have gone wrong when processing discourse? This is what the following sections discuss. 


\section{Naïve optimism}

In ideal circumstances, when interpreting utterances hearers follow the least effort-demanding and most effect-yielding interpretive path. When they arrive at an interpretation that appears optimally relevant, they stop processing and take it to be their interlocutor's informative intention. Accordingly, the comprehension module could be thought to activate some kind of default processing strategy which would be the easiest, simplest and most straightforward available. Sperber (1994) terms this strategy naïve optimism. When individuals resort to it, they behave as naïvely optimistic hearers.

A naïvely optimistic hearer presupposes two fundamental things about his interlocutor:

(i) The speaker is benevolent, i.e. trustworthy, and therefore will not seek to deceive him by providing him with false, unreliable or incomplete information.

(ii) The speaker is competent, i.e. she has an adequate command of the grammatical rules and the norms of usage of the language with which she communicates, and will attempt to provide information that turns out optimally relevant

Consequently, a naïvely optimistic hearer will follow the relevancetheoretic comprehension procedure and will metarepresent his interlocutor's informative intention because he takes for granted the following:

a) The speaker knows the abstract system and the different conventions of meaning and use of the vehicle for communication that she uses.

b) The speaker will try to make manifest her informative intention in the most straightforward way, avoiding ambiguities, vagueness or inaccuracies liable to result in misunderstandings.

c) The speaker, in doing so, will guide the hearer to the intended interpretation in the most efficient way, i.e. the least effortconsuming and most effect-yielding way.

If the speaker is indeed competent and benevolent and does not want to appear otherwise, she will check the following:

a) That the information that she intends to communicate will in fact become optimally relevant to the hearer by producing a satisfactory amount of cognitive effects in exchange of a reasonable amount of cognitive effort. 
b) That the communicative strategy with which she conveys her message is appropriate, i.e. that its pragmalinguistic structure, lexical constituents, syntactic organization and any paralinguistic device he resorts to are not misleading.

c) That the hearer will quickly and easily recover the intended interpretation instead of unintended ones which may appear relevant enough.

If all this applies, the chances for communication to succeed and for the hearer to arrive at the intended interpretation are very high. However, and quite regrettably, communication faces plenty of risks and challenges conducive to failure. When processing utterances at the explicit level, the comprehension module might make mistakes by assigning the wrong reference to referential elements, not disambiguating syntactic structures correctly or not making the appropriate conceptual adjustment, for instance. Likewise, at the implicit level of communication the comprehension module might relate utterances to unintended or inappropriate cultural metarepresentations or manifest contextual assumptions, find it hard to access implicated premises crucial for the derivation of implicatures, or activate inaccurate or inappropriate frames.

On the other hand, the speaker, even if benevolent and trying to appear competent, may not behave in a fully competent manner. She may inadvertently make mistakes when formulating her utterances by using wrong referential elements, inadequate lexical items, inappropriate intonation or selecting inadequate pragmalinguistic strategies. These may misguide the hearer when interpreting the explicit content of utterances. Also, speakers may expect hearers to be able to recover some implicit content on the basis of specific cultural metarepresentations, make-sense frames or manifest assumptions, but they may be unaware that those are unavailable or easily accessible to them, or that their contents vary to a greater or lesser extent. If this happens, hearers may reach unintended interpretations.

If epistemic vigilance acts as a monitor of the interpretive routes hearers opt for, and as a verifier of the credibility and reliability of information sources and the content of the information the comprehension module works with, it might detect that the interpretive hypotheses about both the explicit and implicit content of utterances constructed may be erroneous, inaccurate or inappropriate and, therefore, may prevent the hearer from correctly inferring the speaker's informative intention. Consequently, if it notices that an interpretation reached or reachable when following naïve optimism might not be the intended one, epistemic vigilance might trigger a shift of processing strategy. The following 
sections argue that epistemic vigilance might cause the comprehension module to turn to two more sophisticated processing strategies: cautious optimism or sophisticated understanding (Sperber 1994).

\section{Epistemic vigilance and cautious optimism}

Speakers may inadvertently make mistakes when formulating their messages, which might lead hearers to misunderstand them. Needless to say, hearers may also make interpretive mistakes. If such mistakes went unnoticed, a naïvely optimistic hearer might end up arriving at an interpretation, though seeming relevant enough, is unintended. However, epistemic vigilance could detect those mistakes and prompt a shift to cautious optimism (Sperber 1994).

Cautious optimism entitles a hearer to assume that, even though his interlocutor is benevolent and does not seem to be deceptive, her level of competence might be less than appropriate. Consequently, a cautiously optimistic hearer can realise that an interpretation reached on the grounds of a particular linguistic formulation appearing relevant enough might not be the actually intended one. As a consequence of her cognitive abilities and expressive preferences, the speaker may make slips of the tongue or unfortunate stylistic choices that do not guide the hearer to the most easily accessible and least effort-demanding interpretation. On the contrary, these result in undesired interpretations accidentally achieving relevance or desired interpretations accidentally not achieving relevance (Wilson 1999). To overcome these problems, cautious optimism encourages the hearer to engage in further inferential processes that lead him to abandon an infelicitous interpretation that accidentally appears relevant or irrelevant, and to attribute to his interlocutor the intention to communicate another interpretation that he cannot arrive at because of the speaker's momentary or constant incompetence. But that shift to cautious optimism would not take place unless epistemic vigilance alerts the comprehension module to some inconsistency or flaw in the linguistic formulation or to foreseeable undesired consequences.

On many occasions, speakers select linguistic material that misleads hearers when constructing the explicature of an utterance. For instance, they select wrong lexical items to allude to some entities (1), inappropriate gendered forms of personal pronouns to refer back to a particular individual (2) or deictics which fail to correctly locate an object in space (3): 
(1) Yes, they are building a new sky-scratcher in the city!

(2) And Tom arrived and saw Mary and he said [...] and she [Tom] was very happy to meet her [Mary].

(3) Give me this knife, please!

Epistemic vigilance would warn the comprehension module that the speaker might have unknowingly made a mistake because the resulting interpretation would be at odds with contextual assumptions already manifest, fail to make sense or simply not achieve an optimal level of relevance. Consequently, epistemic vigilance would set cautious optimism in motion, which would encourage the comprehension module to wonder which other lexical item, pro-form or deictic the speaker should have employed, or, alternatively, which referents the speaker would have meant, for the envisaged interpretation to be really optimally relevant.

Epistemic vigilance might also trigger cautious optimism when speakers mispronounce words or have very strong or unfamiliar accents. Mispronunciation or strong accents may make the comprehension module regard what seems to be a hard-to-understand utterance as irrelevant owing to additional load of cognitive effort and prevent it from understanding it. Thanks to cautious optimism, however, the comprehension module would look for alternatives to incomprehensible words or stretches and strive to make sense out of them. For instance, epistemic vigilance seemed not to be fully operative when a Briton congratulated a Canadian father who was explaining that his son was 'autistic'. Not fully understanding the Canadian father's pronunciation, the Brit took the Canadian's pronunciation of the word 'autistic' to mean 'artistic' -which did not at all make sense in that context, though- hence the misunderstanding. Likewise, epistemic vigilance seemed not to work properly when a British Railway waiter gave 'a Hague' (whisky) to an American Southerner who had intended to order 'an egg' for breakfast but pronunced [ยIg] (Wells 1996).

On other occasions, speakers select wrong intonation contours which induce hearers to embed lower-level explicatures under incorrect higherlevel explicatures, as intonation has a procedural meaning that guides the construction of the latter (Wharton 2009). This results in puzzled understanding (Yus Ramos 1999), a misunderstanding which Tannen (1984) observed, for instance, at a canteen where a foreign waiter used a falling intonation instead of a rising one when offering customers gravy. Customers perceived her offer as impolitely imposing. To avoid the misunderstanding, epistemic vigilance should have alerted the customers' comprehension module to the infelicitous intonation and triggered 
cautious optimism. As a result, customers would have discarded the undesired order-interpretation and attributed to the waiter the intention to make an offer, though in a somewhat strange manner.

Quite similarly, many non-native speakers transfer inadequate pragmalinguistic strategies from their L1 to make their informative intention manifest. Since these have a specific meaning or value in the L1, they may cause a native hearer turn an intended explicature into an unintended implicature (Yus Ramos 1999). This is what may happen to waiters when dealing with Spaniards learning English, who directly translate the alerter and head act frequently employed in Spanish to make an order (4) into English (5). Instead of recovering the request- or orderinterpretation, waiters may interpret this sequence as over-imposing, threatening or defiant:

(4) ¡Oiga! Póngame un café

(5) Listen! Put me one coffee / Give me one coffee!

In a case like this, having checked speakers' benevolence, epistemic vigilance would alert the comprehension module to the unfortunate selection of this pragmalinguistic strategy and trigger cautious optimism. Cautious optimism would lead hearers to discard unwanted implicatures of impoliteness or undue imposition and to conclude that the learners' intention was only to order something in a somewhat awkward way because of their low level of competence in the L2.

Although many times individuals' competence as speakers is at stake, other times it is their competence as hearers. Just in the same way speakers' stylistic choices may be unfortunate because of momentary mental limitations or lack of mastery of the linguistic system, hearers may also experience constant or temporary problems when processing utterances. These may result in their reaching unintended interpretations, which they might unfortunately consider to match their interlocutors' informative intention, as such interpretations accidentally seem relevant enough. As a critical alertness to the reliability of communication, epistemic vigilance would monitor comprehension by keeping track of the choices the language and comprehension modules make and the contextual material the latter resorts to. It would assess the accuracy of the interpretive tasks performed, the believability and suitability of the information employed, the reliability of the interpretive routes taken and the potential plausibility, correctness and relevance of the interpretation selected. Thus, epistemic vigilance might spot flaws and trigger cautious optimism, if it detects that those modules perform inefficiently or ultimately feels that the hearer's competence is momentarily impaired. 
At the explicit level of communication, epistemic vigilance can notice that an explicature might be unintended because of errors in reference assignment (6), disambiguation $(7,8)$ or conceptual adjustment (9). As a result, epistemic vigilance would enact cautious optimism so that the comprehension module searches for alternative referents, parses ambiguous syntax differently or narrows or broadens concepts as expected:

(6) Leave it there! (there $=$ on the table? on the shelf?)

(7) John saw the man with the red glasses. (John saw [the man with the red glasses]]/[John saw [the man] [with the red glasses]]?)

(8) They are hunting dogs. ([They are hunting [dogs]]/[They are [hunting dogs]]?)

(9) Martha cut the tree. (Martha *CUT the tree [an ad-hoc concept referring to a particular type of cutting -with a saw instead of with scissors, for instance])

Epistemic vigilance can also detect that a belief the hearer holds (10) may induce him to build an erroneous higher-level explicature and misinterpret the illocutionary force of an utterance -for instance, as a criticism or sarcasm instead of as praise or compliment (11):

(10) Peter disapproves of women wearing mini-skirts to attend religious services.

(11) Oh, cute skirt! ([Context: right before a religious service] irony, sarcasm, implicit criticism, complaint...?)

Upon detecting that the interpretation reachable on the grounds of that belief might conflict with, for example, manifest contextual elements like paralanguage (gestures, face-expression, etc.), epistemic vigilance would instruct the comprehension module to enact cautious optimism in order to revise the belief entertained and, if necessary, entertain another which makes it possible to arrive at another interpretation that achieves an optimal level of relevance and turns out to be more consistent with what is perceived.

At the implicit level of communication, epistemic vigilance can also alert the comprehension module that an implicature (14) might be unintended because the comprehension module unnecessarily took the explicature of an utterance (12) as input to further inferential processes, in which it was related to unwarranted implicated premises (13): 
[Context: two friends strolling aimlessly down the street, without a clear direction]

(12) It is 20.20 ! (intended as a phatic remark)

(13) a. Shops close at 20.30.

b. Speaker might want to buy something

(14) We should hurry up!

Cautious optimism being triggered, the comprehension module would discard such implicated premises and backtrack to the explicit interpretation of the utterance.

Quite similarly, epistemic vigilance can also find an initial explicit interpretation (16) of an utterance (15) not to be optimally relevant and feel that the speaker might have intended to convey some implicit content. Since the comprehension module has initially failed to arrive at it, cautious optimism aids in helping the hearer search for the necessary implicated premises (17) that yield such implicit content (18):

[Context: Mary's birthday is approaching. Mary and Peter are windowshopping]

(15) Mary: Isn't that mobile cute? I love it! It must be fab!

(16) Mary loves that mobile.

(17) a. Mary's birthday is approaching.

b. Mary loves technology gadgets.

c. A mobile is an excellent birthday present.

(18) Mary might be suggesting that he would love a new mobile as a birthday present.

Finally, epistemic vigilance could also sense that an implicature that the comprehension module arrives at differs from what the speaker could have wanted to convey -i.e. is an alternative implicature (Yus Ramos 1999)- because the comprehension module has relied on cultural or contextual assumptions different from those that the speaker might have expected the hearer to resort to. Cross-cultural encounters attest this type of misunderstanding. For instance, Reynolds (1995) reports that Finnish students were surprised and even bothered by their British mates' small talk in some situations. Having perceived their benevolence, epistemic vigilance should have triggered cautious optimism so that the Finnish students would have discarded cultural assumptions referring to the inconvenience of small talk in those situations and have processed it against other assumptions. This would have led them to a more plausible, optimally relevant interpretation of that conversational behaviour. 


\section{Epistemic vigilance and sophisticated understanding}

Communication is an ostensive-inferential activity in which the speaker draws the hearer's attention because she has an informative intention (Sperber and Wilson 1986, 1995). The hearer must infer that intention from utterances, which are indirect, more or less reliable, evidence of what the speaker intends to communicate. However, on many occasions, and for many reasons, an utterance is unreliable because the speaker does not actually have the informative intention that she appears to have, but some hidden intention. Thus, instead of behaving benevolently and sincerely, and so choosing the ostensive stimulus that most directly guides the hearer to her informative intention with the least effort, the speaker may behave malevolently or deceptively and select stimuli that make the hearer attribute to her an informative intention that differs from her actual one.

Communication also presupposes a communicative intention that triggers the hearer's search for the speaker's informative intention. When hearers take for granted that speakers are benevolent and competent, they may think that an interpretation that they reach and find optimally relevant corresponds to the speakers' informative intention. Therefore, hearers need not worry about the existence of alternative interpretations, which speakers might have purported to communicate. If hearers assume that speakers, though benevolent, are not (fully) competent, they ought to conclude that the speakers' intention may be to communicate another interpretation and not one that only seems relevant and does not correspond to their real informative intention. If hearers feel that their own interpretive skills are impaired, they must deduce that they might not have reached the intended, optimally relevant interpretation. In these two scenarios, epistemic vigilance would alert to speakers' or hearers' incompetence and trigger cautious optimism, as a consequence of which the comprehension module would continue processing and search for more plausible interpretations. Cautious optimism triggered, hearers can question the outcomes of interpretive tasks, distrust some beliefs they could have held and wonder which other informative intention their interlocutors might have but fail to make manifest in the most efficient way or they themselves fail to infer. Consequently, hearers can attribute different beliefs and intentions to their interlocutors, who failed to be optimally relevant even though they attempted to be, or which they unfortunately were unable to perceive.

Finally, when epistemic vigilance cautions the comprehension module that the speaker is competent but is not behaving benevolently, it would enact an even more complex processing strategy: sophisticated understanding (Sperber 1994). When following this strategy, a hearer is 
capable of inferring another interpretation that would indeed have been optimally relevant but which, for whatever reason, the speaker refrains from transmitting or prevents the hearer from reaching in the easiest way. As Wilson (1999: 138) explains, a sophisticated hearer uses his metarepresentational abilities in order to face utterances wherewith his interlocutor only tries to communicate an interpretation that seems to be relevant but is not the actually intended one. Consequently, a sophisticated hearer does not stop his processing at the first interpretation that he finds optimally relevant, or at the interpretation that he considers the speaker might have expected to appear optimally relevant.

Epistemic vigilance could detect (i) that the speaker attempts to bias the hearer to some parsing, disambiguation, reference assignment or conceptual adjustment that would prevent him from reaching a certain envisaged interpretation which would have achieved optimal relevance, (ii) that the speaker guides the hearer to use implicated premises or to activate mental frames unsuitable for reaching a real interpretation, or (iii) that the comprehension module needs other contextual information in order to infer that interpretation. Therefore, it would trigger sophisticated understanding so that the comprehension module revises or continues its interpretive task until it deduces the interpretation which the speaker avoids communicating in the most direct and effort-saving way. Epistemic vigilance would be able to realise the existence of alternative parsings, disambiguation, reference assignment, conceptual adjustment, implicated premises or mental frames conducive to the interpretation that the speaker attempts to prevent the hearer from reaching. Thus, it would prompt the comprehension module not to regard a first interpretation appearing optimally relevant as the speaker's informative intention, but as incorrect and misleading. On the contrary, upon detecting the feasibility of other interpretive routes and outcomes of interpretive tasks, epistemic vigilance would instruct the comprehension module to search for another interpretation which the speaker, for some reason, refrains from communicating. To do so, the comprehension module would follow the path it senses will require the least effort and will yield the highest amount of cognitive benefits.

Epistemic vigilance appears essential in exchanges in which speakers intentionally seek or seem to deceive hearers, i.e. in cases in which hearers are led to entertain, and ultimately believe, an interpretation that does not correspond to the speaker's real informative intention. Indeed, the speaker does her best to mislead the hearer by making an unintended interpretation appear very easily accessible, costless, plausible and, therefore, optimally relevant. However, that interpretation is not the one that the hearer should 
infer. In addition to lies, this happens, for instance, in some types of humour, like jokes.

When telling jokes, speakers move to a non-bona-fide mode of communication (Raskin 1985; Attardo 1990, 1993) or to a humorous frame (Yamaguchi 1988), sometimes explicitly indicated by linguistic markers. They play with language, hearers' interpretive capabilities and the likelihood that some interpretations become more or less salient in order to deceive hearers (Yus Ramos 2008: 133). Jokers do not deceive their audience by lying, but by fooling them or pulling their $\operatorname{leg}^{2}$. Jokers intentionally mislead hearers to some interpretation, try to make them reach it, consider it optimally relevant and ultimately believe it to be the intended one. But hearers must realise that they are being or have been misguided, backtrack and reinterpret the text (McGhee 1972; Attardo 1993: 551). Thus, they can discard a (literal) bona-fide interpretation, which they probably infer following naïve optimism ${ }^{3}$. As Attardo (1993: 550) puts it, the joker tries to "[...] actually 'fool' his/her [audience] into believing that 'normal' bona-fide text will follow, only to deceive his/her audience, and deliver instead the unexpected punch line"4.

Reaching the authentic interpretation requires in many cases more effort-demanding interpretive routes, which the joker favours, maybe with the tacit promise of an increase in humorous effects which could not be achieved otherwise (Yus Ramos 2003: 1298-1299). Jokers can intentionally mislead or fool the audience, firstly, because they exploit the pragmatic ambivalence of utterances, which may potentially have a variety of interpretations, all of which compatible with the information linguistically encoded. Jokers are aware that the hearers' comprehension module will not access or juggle with all of them at the same time, as some may be more salient and difficult to put down in a particular context (Peleg et al. 2008), while others look costlier. The hearer will select one interpretation and exclude competing ones on the basis of considerations

\footnotetext{
2 This seems crucial for jokes to fulfil some social functions like decommitment and group identification (Attardo 1993: 554-556). However, this does not operate in subversive humour, where humourists make fun of established norms, rules, practices, etc. in some contexts, like the workplace (Schnurr and Rowe 2008) or schools (Norrick and Klein 2008).

3 Raskin (1985), Attardo (1990, 1993) and Raskin and Attardo (1994) have accounted for the interpretation of jokes on the basis of the Gricean Cooperative Principle and its maxims. Since Relevance Theory goes well beyond them and rejects their existence, no further explanation of jokes along them will be done.

${ }^{4}$ For a slightly different proposal, see Dynel (2008: 174-176).
} 
of cognitive effort and reward (Wilson 1993; Wilson and Sperber 2002, 2004).

Secondly, jokers can mislead hearers because, so to say, they can read hearers' minds. Jokers can predict to some extent which cognitive operations their comprehension module might perform, which contextual information it will access, which inferential routes it might follow and potential outcomes of those operations (Wilson and Sperber 2002, 2004). Hence, jokers rely on their mind-reading ability and "[...] predict that certain stimuli will be more relevant than others and that certain assumptions will inevitably be entertained by their audience during comprehension" (Yus Ramos 2008: 140). Accordingly, in many cases jokers devise jokes in such a way that the audience uses initial and next fragments as an interpretive context against which to process subsequent information (Yus Ramos 2008: 140). They manipulate this context so that the audience is made believe that the joke -or some fragment(s)- has a first -or several- highly salient and easily accessible, but wrong, interpretation(s) -the multiple-graded-interpretation (MGI) part of the joke, as Yus Ramos (2003: 1309) labels it. Nevertheless, the following fragment has a single interpretation which surprises or shocks the audience -the single-covert-interpretation (SCI) part of the joke (Yus Ramos 2003: 1309)- because of its incongruity with the initial or preceding fragment. The hearer is surreptitiously led to entertain an incorrect interpretation in the MGI part of the joke, so what triggers humour is "The resolution of the incongruity, by finding one overall coherent sense of the whole text, together with the realization of having been fooled into selecting specific interpretation [...]" (Yus Ramos 2003: 1309) ${ }^{5}$. The resolution of the incongruity depends on some kind of cognitive rule which reconciles the incongruous part of the joke (Suls 1972). Such rule can be "[...] semantic, logical, or experiential [...]" and "[...] is identified through a problem solving activity" (Forabosco 2008: 47). It involves "[...] an element of sense, a criterion which renders the stimulus cognitively acceptable" (Forabosco 2008: 49) ${ }^{6}$. Upon realising that the comprehension module has been or is being fooled, epistemic vigilance would contribute to the resolution of incongruities by enacting sophisticated understanding and discovering such a rule or criterion.

\footnotetext{
5 Yus Ramos' (2003) account of jokes is in line with Suls' (1972) incongruityresolution model and other related proposals (e.g. Forabosco 1992; Attardo 1994, 1997). For criticism, see Forabosco (2008: 55-57).

${ }^{6}$ Suls (1983) concluded that, while some types humour may rely on the perception and resolution of incongruities, other types may only rely on their perception.
} 
Since jokers can predict how hearers might process jokes and are aware of possible ambiguities of linguistic structures, salient information, etc., they try to create humour by manipulating hearers' interpretive steps at both the explicit and implicit level of communication (Yus Ramos 2008). As regards the explicit level of communication, jokers try to fool their audience at the different stages of comprehension, from the identification of the logical form, to reference assignment, disambiguation, conceptual adjustment or the construction of higher-level explicatures. Consider firstly the identification of logical forms. Many humourists bias their audience to a specific ascription of meaning or to an initial syntactic parsing, which must be subsequently invalidated to achieve humorous effects (Yus Ramos 2008: 145-146). This can be seen in jokes (19) and (20):

(19) Why did the blonde take a ladder into the bar? She heard the drinks were on the house.

(20) The blonde walks into a drugstore and asks the pharmacist for some bottom deodorant. The pharmacist, a little bemused, explains to the woman that they don't sell anything called 'bottom deodorant', and never have. Unfazed, the blonde assures him that she has been buying the stuff from this store on a regular basis, and would like some more. "I'm sorry," says the pharmacist, "we don't have any." "But I always get it here," says the blonde. "Do you have the container it comes in?" "Yes!", says the blonde, "I will go and get it." She returns with the container and hands it to the pharmacist, who looks at it and says to her, "This is just a normal stick of underarm deodorant." The annoyed blonde snatches the container back and reads out loud from the container: "To apply, push up bottom."

In (19) the joker makes the audience firstly regard as optimally relevant the likely, very salient, but eventually incorrect, interpretation "the house will pay for the drinks". However, the correct interpretation is "drinks are located on top of the house". Epistemic vigilance must detect that such initial ascription of meaning to the phrase "drinks were on the house" is unviable and make the language module backtrack so as to realise that a different, locative meaning for the expression "were on the house", which did not initially achieve optimal relevance, can be more viable. Although this backtracking involves some cognitive effort, this is offset by additional cognitive effects, such as realisation of having been fooled, which would be responsible for potential humorous effects in that somewhat strange context of a blonde going to a bar with her ladder. In (20), apart from the ambiguity of the word 'bottom', the joker plays with two possible ways of parsing the string "push up bottom" -[push up] 
[bottom] vs. [push] [up bottom]- making the former very salient in that scenario. However, for humour to arise, epistemic vigilance should alert the comprehension module that such parsing, even if grammatically expectable, is inadequate. This would activate sophisticated understanding, which would result in the comprehension module considering the other parsing as necessary to grasp the humour in this situation.

Jokers also exploit the way they think the audience will assign reference to some pro-forms (Yus Ramos 2008: 146), as in (21) and (22):

(21) Said the Buddhist to the hotdog vendor: "Make me one with everything."

(22) A husband and wife came for counselling after 20 years of marriage. When asked what the problem was, the wife went into a passionate, painful tirade listing every problem they had ever had in the 20 years they had been married. She went on and on and on: neglect, lack of intimacy, emptiness, loneliness, feeling unloved and unlovable, an entire laundry list of unmet needs she had endured over the course of their marriage. Finally, after allowing this to go on for a sufficient length of time, the therapist got up, walked around the desk and, after asking the wife to stand, embraced and kissed her passionately as her husband watched with a raised eyebrow. The woman shut up and quietly sat down as though in a daze. The therapist turned to the husband and said, "This is what your wife needs at least three times a week. Can you do this?" The husband thought for a moment and replied, "Well, I can drop her off here on Mondays and Wednesdays, but on Fridays, I fish."

In (21) the joker makes the Buddhist echo Dalai Lama's famous motto, but with evidently different meaning and overtones. For humour to arise, epistemic vigilance must alert the comprehension module to the different referential candidates for 'one' ('hotdog' vs. 'oneself') and 'everything' ("all the toppings, ingredients" vs. "the universe"). Probably, the easiest way of assigning reference to the Buddhist's words is "make me one hotdog with all the toppings", but humour might reside in the absurd possibility that the Buddhist is asking the vendor to enlighten him by "making him one being with all the toppings that the vendor has in his stall". Having noticed the unsuitability of such reference assignment for the achievement of humour, epistemic vigilance would instruct the comprehension module to activate sophisticated understanding in order to assign reference in the way in which the joker would have prevented the hearer from making. Quite similarly, (22) plays with different referential candidates for "do this". While the joker seems to guide the audience to 
take it to refer to the husband embracing and kissing the wife passionately, epistemic vigilance must discover that the joker did not actually intend that highly salient referent. Upon cautioning the comprehension module about its unlikelihood, sophisticated understanding must be enacted in order to access another covert referent: the husband taking his wife to the therapist for the therapist himself to embrace and kiss her passionately, not the husband.

Senses of words or phrases are also manipulated by jokers to produce humorous effects (Yus Ramos 2008: 146-149), as in (23-25):

(23) Question: Why did the bald man paint rabbits on his head? Answer: Because from a distance they looked like hares!

(24) "Please remove your blouse and bra," says the doctor to the young blonde, placing his stethoscope around his neck. When she is ready, the doc says, "Big breaths." "Yeth," she replies, "and I'm only thixthteen!'

(25) Question: What can a goose do, that a duck can't do and a lawyer should do?

Answer: Stick his bill up his ass.

In (23) the humourist plays with the homophony between 'hares' and 'hairs', in (24) with 'breaths' resembling 'breasts' when pronounced with lisping, and in (25) with 'bill' being polysemous ('beak' vs. 'invoice'). The audience may be initially led to interpret these words as having a primary sense in those contexts, but epistemic vigilance must alert the comprehension module to the incorrectness of their disambiguation of sense so that it considers alternative senses on the assumption that there will be a humorous reward. Consequently, the comprehension module will engage in sophisticated understanding in order to track the intended sense that the joker might have envisaged in order to produce humour.

Other jokes depend on the conceptual adjustment -narrowing or broadening- which the audience makes, as they contain metaphors (Yus Ramos 2008: 149-150):

(26) A large, powerfully-built guy meets a woman at a bar. After a number of drinks, they agree to go back to his place. As they are making out in the bedroom, he stands up and starts to undress. After he takes his shirt off, he flexes his muscular arms and says, "See that, baby? That's 1000 pounds of dynamite!" She begins to drool. The man drops his pants, strikes a bodybuilder's pose, and says, referring to his bulging thighs, "See those, baby? That's 1000 pounds of dynamite!" She is aching for action at this point. Finally, he drops his underpants, and after a quick glance, she grabs her purse and runs screaming to 
the front door. He catches her before she is able to leave and asks, "Why are you in such a hurry to go?" She replies, "With 2000 pounds of dynamite and such a short fuse, I was afraid you were about to blow!"

(27) A little boy says: "Daddy, how was I born?" Dad says: “Ah, my son. I guess one day you will need to find out anyway! Well, you see, your Mom and I first got together in a chat room on MSN. Then I set up a date via e-mail with your mom and we met at a cyber-cafe. We sneaked into a secluded room, where your mother agreed to a download from my hard drive. As soon as I was ready to upload, we discovered that neither one of us had used a firewall, and since it was too late to hit the delete button, nine months later a blessed popup appeared and said: 'You've Got Male!'”

The role of epistemic vigilance when processing these jokes would be to check that the comprehension module adjusts the meaning of words like 'dynamite', 'fuse' and 'blow' in (26), and 'download', 'hard drive', 'upload', 'firewall', etc. in (27) as the joker would have envisaged. If it feels that this has not been correctly done, it would prompt the comprehension module to engage in sophisticated understanding in order to broaden them in such a way that the properties stereotypically associated with 'dynamite' and 'fuse' can also be extended to the powerfully-built guy's anatomy or those of 'download', 'hard drive', 'upload', 'firewall', etc. can be applied to the description of the undesired pregnancy.

Finally, other jokes achieve humour because the audience is led to think that some of the characters in them would construct specific higherlevel explicatures for some utterances (Yus Ramos 2008: 150-151). For instance, in (28) the audience is guided to believe that the higher-level explicature that the guy would construct for "Take that sheep to the zoo" amounts to command or order:

(28) A guy found a sheep and showed him to a policeman. The policeman said, "Take that sheep to the zoo, now." Next day the policeman sees the man with the sheep again. The policeman stops the guy and says, "What on earth are you doing with that sheep?" The guy says, "What is there to do? Yesterday I took him to the zoo and now I'm taking him to the movies."

Epistemic vigilance must discover that the higher-level explicature that the character is thought to construct is not the one that the character actually constructs. Hence, it must instruct the comprehension module to 
consider an alternative hypothesis about the higher-level explicature, which, for this joke to be funny, would be one of advice or suggestion.

Regarding the implicit level of communication, many jokes achieve humorous effects as a consequence of a clash between explicit information contained in the joke and the beliefs that the audience is led to retrieve or construct (Curcó 1995, 1996), the initial use of inappropriate or incorrect implicated premises that must be subsequently invalidated (Yus Ramos 2003, 2008) or the activation of cultural or make-sense frames that must be later on discarded (Yus Ramos, forthcoming a). The explicit content of some jokes makes some target assumptions -as Curcó $(1995,1996)$ terms them- strongly manifest, but these turn out inappropriate or incorrect to grasp the humour. Epistemic vigilance would detect this and trigger sophisticated understanding, as a result of which the comprehension module would search for (an)other key assumption(s) which the joker intended not to make easily or straightforwardly accessible at the beginning of the joke. This happens in the following jokes:

(29) Mom and Dad were trying to console Susie, whose dog had recently died. "You know," Mom said, "it's not your fault that the dog died. He's probably up in heaven right now, having a grand old time with God." Susie, still crying, said, "What would God want with a dead dog?",

(30) Two blondes are waiting at a bus stop. When a bus pulls up and opens the door, one of the blondes leans inside and asks the bus driver: "Will this bus take me to $5^{\text {th }}$ Avenue?" The bus driver shakes his head and says, "No, I'm sorry." At this the other blonde leans inside, smiles, and twitters: "Will it take ME?"

(29) makes strongly manifest the target assumption that dead dogs might have a grand time in heaven. Epistemic vigilance must discard it in favour of the key assumption that dead dogs cannot have a grand time there precisely because they are dead. In turn, in (30) the audience is initially led to entertain and believe an assumption such as that the bus is not going to $5^{\text {th }}$ Avenue. However, epistemic vigilance must discover its incorrectness so that the comprehension module accesses another contextual assumption, such as that the second blonde believes the bus driver not to be willing to take her friend but might want to take her there.

In addition to the assumptions that the joke makes manifest, many jokes require for the audience to look for implicated premises that yield implicated conclusions in which humour resides (Yus Ramos 2008: 152153). The role of epistemic vigilance in these jokes would precisely be to alert the comprehension module of the unsuitability of the explicit 
interpretation reachable for achieving humorous effects and to trigger sophisticated understanding so that the comprehension module expands the initial context by incorporating the necessary implicated premises to understand the joke and its humour. Accordingly, enacting sophisticated understanding when processing (31) and (33) would make it possible for the audience to access the implicated premises in (32 a, b) and (34 a, b, c), which would yield the implicated conclusions (32 c) and (34 d), respectively:

(31) Little Nancy was in the garden filling in a hole when her neighbour peered over the fence. Interested in what the little girl was up to, he politely asked, "What are you up to there, Nancy?" "My goldfish died," replied Nancy tearfully, without looking up, "and I've just buried him." The neighbour was concerned, "That's an awfully big hole for a goldfish, isn't it?" Nancy patted down the last heap of earth and then replied, "That's because he's inside your stupid cat."

(32) a. The girl has killed the cat.

b. A girl who can kill a cat is cruel and remorseless.

c. Little Nancy is cruel and remorseless.

(33) There were four country churches in a small Texas town: The Presbyterian Church, the Baptist Church, the Methodist Church and the Catholic Church. Each church was overrun with pesky squirrels. One day, the Presbyterian Church called a meeting to decide what to do about the squirrels. After much prayer and consideration they determined that the squirrels were predestined to be there and they shouldn't interfere with God's divine will. In the Baptist Church the squirrels had taken up habitation in the baptistery. The deacons met and decided to put a cover on the baptistery and drown the squirrels in it. The squirrels escaped somehow and there were twice as many there the next week. The Methodist Church got together and decided that they were not in a position to harm any of God's creation. So, they humanely trapped the Squirrels and set them free a few miles outside of town. Three days later, the squirrels were back. But... The Catholic Church came up with the best and most effective solution. They baptized the squirrels and registered them as members of the church. Now they only see them on Christmas and Easter.

(34) a. Catholics are not (supposed to be) very committed believers.

b. Stereotypical uncommitted Catholics very rarely go to church.

c. Stereotypical uncommitted Catholics (are said to) only go to church on special occasions.

d. The squirrels behaved as stereotypical Catholics.

Finally, in many jokes humourists play with the initial activation of cultural and make-sense frames (Yus Ramos, forthcoming a), which subsequently prove to be inappropriate, so that the comprehension module 
has to abandon them in favour of other more specific frames ${ }^{7}$. Consider (35) and (36):

(35) An old lady sits on her front porch, rocking away the last days of her long life, when all of a sudden, a fairy godmother appears and informs her that she will be granted three wishes. "Well, now," says the old lady, "I guess I would like to be really rich." *** POOF *** Her rocking chair turns to solid gold. "And, gee, I guess I wouldn't mind being a young, beautiful princess." *** POOF *** She turns into a beautiful young woman. "Your third wish?" asks the fairy godmother. Just then the old woman's cat wanders across the porch in front of them. "Ooh, can you change him into a handsome prince?" she asks. *** POOF *** There before her stands a young man more handsome than anyone could possibly imagine. She stares at him, smitten. With a smile that makes her knees weak, he saunters across the porch and whispers in her ear, "Bet you're sorry you had me neutered."

(36) John and Bob were inseparable childhood friends. One night, they both died in a terrible car accident. When John woke up in heaven, he began to search for Bob but could not find him anywhere. Very distraught, he ran to St. Peter and said, "St. Peter, I know Bob was killed in that accident with me, but I can't find him!" St. Peter said, "My son, I am sorry to tell you Bob didn't make it to Heaven." This upset John so much that St. Peter agreed to let him see Bob one more time. St. Peter parted the clouds and John saw Bob sitting in hell with a keg on one side and a beautiful buxom blonde on the other. John looked at St. Peter sceptically and said, "Are you sure I' $m$ in the right place?" "My son," St. Peter said, "looks can be deceiving. You see that keg of beer? It has a hole in it. You see that woman? She doesn't!"

In (35) the audience is guided to initially activate a cultural frame related to nice old ladies calmly and quietly living their last days at home and fairy godmothers granting wishes. They also have to activate the makesense frame of the old lady wanting a handsome prince in order to have sex. Epistemic vigilance would check that the latter frame, even if potentially valid, must be rejected at the end of the joke because the cat changed into a prince had been neutered. Therefore, epistemic vigilance would have to instruct the comprehension module to activate a quite

\footnotetext{
${ }^{7}$ Yus Ramos (forthcoming a) classifies of jokes depending on whether they target at utterance interpretation processes -logical forms, disambiguation, etc.- or the activation of cultural or make-sense frames in what he labels the Intersecting Circles Model. Humorous effects are argued to arise as a consequence of manipulating one or a combination of them. Due to space limitations, this discussion will only deal with two examples.
} 
different frame, for instance, one about old ladies eager for sexual intercourse with handsome guys and disappointment at being unable to have it. On the other hand, in (36) the audience is induced to activate a religious cultural frame in which good guys go to heaven and bad guys to hell. Such frame can be questioned when another make-sense frame related to kegs of beer and beautiful women is activated. This contradicts what souls are supposed to enjoy in heaven and hell. The contradiction between both frames is solved at the end of the joke, where the pun on 'holes' appears. As a consequence, epistemic vigilance must discover that the comprehension module was fooled into activating that initial makesense frame and must hence discard it. Hence, epistemic vigilance must prompt the comprehension module to activate an alternative frame about tricky kegs of beer and deceptive appearances.

\section{Conclusion}

Understanding utterances is a relevance-driven activity in which the language and comprehension module rely on the linguistic evidence provided and contextual information in order to perform a series of tasks whose result is an interpretation. For the hearer to finally believe that interpretation, he must be certain that it was the interpretation that the speaker actually intended, that the speaker is a trustworthy, reliable and skilled communicator and that he did not make any interpretive mistake. Epistemic vigilance can be seen as a surveillance mechanism playing an essential role in giving credit to our interlocutors, the information that they dispense, how they communicate it, how we process it and which other information we make use when processing it. As such, it would not enter the scene after the final product of comprehension -the interpretation- is reached; rather, it would be operative at every task which the comprehension module performs. Therefore, epistemic vigilance should not be conceived of as a module performing a final test on interpretations, but as an independent module working as comprehension proceeds.

In spite of its independence, its working affects the working of the comprehension module. If epistemic vigilance finds out that speakers make unfortunate linguistic choices which prevent hearers from reaching the intended interpretation, that the language or comprehension modules make mistakes or that speakers seek to mislead or deceive hearers, it instructs the comprehension module to enact cautious optimism or sophisticated understanding. The former enables hearers to overcome expressive and interpretive mistakes by means of a first-order 
metarepresentation of speakers' informative intention (Wilson 1999) or by searching for more suitable explicatures and implicatures. As a result, hearers can conclude that speakers were mistaken when saying what they said in the way they did or that they misunderstood their interlocutors. Thus, cautious optimism enables hearers to discard accidentally relevant or irrelevant unintended interpretations. As a consequence of the latter, hearers can overcome deception or grasp humorous effects thanks to second-, third- or fourth-order metarepresentations (Curcó 1995, 1996; Wilson 1999), from which they can conclude that speakers are lying, trying to convince them of something contradictory or are humorous. Thus, sophisticated understanding makes it possible for hearers to discard interpretations which speakers attempt to present as optimally relevant and believable, but are not actually the real, believable interpretations or those necessary to achieve effects like humour.

Sperber (1994) and Wilson (1999) described these two processing strategies, but they did not explain why the comprehension module opts for one or the other. This paper has suggested that the enactment of either strategy follows as a consequence of epistemic vigilance and the search for optimal relevance. It has illustrated this by means of specific cases of misunderstandings and jokes. The same argument could be extended to other relatively similar phenomena, for example, to puns (e.g. Tanaka 1992), with which the communicator misguides the audience to highly salient, maybe equally accessible, interpretations, but intends the audience to reach one interpretation, and also to those interpretations that radically differ from the explicit content, as in some innovative ironies (Yus Ramos, personal communication). In these, the explicit interpretation clashes with contextual information. Upon noticing that the speaker might have intended an interpretation of these utterances despite such clash, epistemic vigilance would prompt the comprehension module to search for a more implicit (i.e. ironic) interpretation (Yus Ramos 2012, forthcoming b). A more detailed analysis of these phenomena should be the subject for future work.

\section{References}

Attardo, Salvatore. 1990. The violation of Grice's maxims in jokes". In K. Hall et al. (eds.), Proceedings of the $16^{\text {th }}$ Berkeley Linguistics Society Conference. Berkeley: University of California Press, 355-362.

Attardo, Salvatore. 1993. Violation of conversational maxims and cooperation: the case of jokes. Journal of Pragmatics 19: 537-558. 
Attardo, Salvatore. 1994. Linguistic Theories of Humor. Berlin: Mouton de Gruyter.

Attardo, Salvatore. 1997. The semantic foundations of cognitive theories of humor. Humor 10(4): 395-420.

Carston, Robyn. 2002. Thoughts and Utterances. The Pragmatics of Explicit Communication. Oxford: Blackwell.

Carston, Robyn. 2010. Lexical pragmatics, ad hoc concepts and metaphor: from a relevance theory perspective. Italian Journal of Linguistics 22(1): 153-180.

Curcó, Carmen. 1995. Some observations on the pragmatics of humorous interpretations. A relevance-theoretic approach. UCL Working Papers in Linguistics 7: 27-47.

Curcó, Carmen. 1996. The implicit expression of attitudes, mutual manifestness and verbal humour. UCL Working Papers in Linguistics 8: 89-99.

Dynel, Marta. 2008. There is method in the humorous speaker's madness: humour and Grice's model. Lodz Papers in Pragmatics 4(1): 159-185.

Forabosco, Giovannantonio. 1992. Cognitive aspect of the humor process: the concept of incongruity. Humor 5(1-2): 45-68.

Forabosco, Giovannantonio. 2008. Is the concept of incongruity still a useful construct for the advancement of humour research? Lodz Papers in Pragmatics 4(1): 45-62.

Mascaro, Olivier and Dan Sperber. 2009. The moral, epistemic, and mindreading components of children's vigilance towards deception. Cognition 112(3): 367-380.

McGhee, Paul. 1972. On the cognitive origins of incongruity humor: fantasy assimilation versus reality assimilation. In J. H. Goldstein and P. E. McGhee (eds.), The Psychology of Humor. London: Academic Press, 61-80.

Norrick, Neal R. and Janine Klein. 2008. Class clowns: talking out of turn with an orientation toward humor. Lodz Papers in Pragmatics 4(1): 83-107.

Oswald, Steve. 2011. From interpretation to consent: arguments, beliefs and meaning. Discourse Studies 13(6): 806-814.

Padilla Cruz, Manuel. In press. Understanding and overcoming pragmatic failure in intercultural communication: from focus on speakers to focus on hearers. International Review of Applied Linguistics in Language Teaching.

Padilla Cruz, Manuel. Forthcoming. Epistemic vigilance and pragmatic failure in interlanguage interaction. 
Peleg, Orna, Rachel Giora and Ofer Fein. 2008. Resisting contextual information: You can't put a salient meaning down. Lodz Papers in Pragmatics 4(1): 13-44.

Raskin, Victor. 1985. Semantic Mechanisms of Humor. Dordrecht: Reidel. Raskin, Victor and Salvatore Attardo. 1994. Non-literalness and non-bonafide in language: an approach to formal and computational treatments of humor. Pragmatics and Cognition 2: 31-69.

Reynolds, Mike. 1995. Where the trouble lies: cross-cultural pragmatics and miscommunication. Papers and Studies in Contrastive Linguistics 30: 5-15.

Schnurr, Stephanie and Charley Rowe. 2008. The 'dark side' of humour. An analysis of subversive humour in workplace emails. Lodz Papers in Pragmatics 4(1): 109-130.

Sperber, Dan. 1994. Understanding verbal understanding. In J. Khalfa (ed.), What Is Intelligence? Cambridge: Cambridge University Press, 179-198.

Sperber, Dan. 1996. Explaining Culture. A Naturalistic Approach. Oxford: Blackwell.

Sperber, Dan and Deirdre Wilson. 1986. Relevance. Communication and Cognition. Oxford: Blackwell.

Sperber, Dan and Deirdre Wilson. 1995. Relevance. Communication and cognition. $2^{\text {nd }}$ edn. Oxford: Blackwell.

Sperber, Dan et al. 2010. Epistemic vigilance. Mind and Language 25(4): 359-393.

Suls, Jerry M. 1972. A two-stage model for the appreciation of jokes and cartoons". In Jeffrey H. Goldstein and Paul E. McGhee (eds.), The Psychology of Humor: Theoretical Perspectives and Empirical Issues. New York: Academic Press, 81-100.

Suls, Jerry M. 1983. Cognitive processes in humor appreciation. In Paul E. McGhee and Jeffrey H. Goldstein (eds.), Handbook of Humor Research (I). New York: Springer, 39-57.

Tanaka, Keiko. 1992. The pun in advertising: a pragmatic approach. Lingua 87: 91-102.

Tannen, Deborah. 1984. The pragmatics of cross-cultural communication. Applied Linguistics 5: 188-195.

Thomas, Jenny. 1983. Cross-cultural pragmatic failure. Applied Linguistics 4: 91-112.

Unger, Christoph. 2012. Epistemic vigilance and the function of procedural indicators in communication and comprehension. In E. Wałaszewska and A. Piskorska (eds.), Relevance Theory. More than 
Understanding. New Castle upon Tyne: Cambridge Scholars Publishing, 45-73.

Wells, John. 1996. Accents of English 1: An Introduction. Cambridge: Cambridge University Press.

Wharton, Tim. 2009. Pragmatics and Non-verbal Communication. Cambridge: Cambridge University Press.

Wilson, Deirdre. 1993. Relevance and understanding. Pragmalingüística 1: 335-366.

Wilson, Deirdre. 1999. Metarepresentation in linguistic communication. UCL Working Papers in Linguistics 11: 127-161.

Wilson, Deirdre. 2011. Understanding and believing. Paper presented at Relevance Round Table (Meeting 3). Warsaw: Institute of English Studies, University of Warsaw.

Wilson, Deirdre. 2012a. Relevance theory and the interpretation of literary works Paper presented at the $5^{\text {th }}$ International Symposium on Intercultural, Cognitive and Social Pragmatics (EPICS V). Seville: Pablo de Olavide University.

Wilson, Deirdre. 2012b. Modality and the conceptual-procedural distinction. In E. Wałaszewska and A. Piskorska (eds.), Relevance Theory. More than Understanding. New Castle upon Tyne: Cambridge Scholars Publishing, 24-43.

Wilson, Deirdre and Dan Sperber. 2002. Relevance theory. UCL Working Papers in Linguistics 14: 249-287.

Wilson, Deirdre and Dan Sperber. 2004. Relevance Theory. In L. Horn and G. Ward (eds.), The Handbook of Pragmatics. Oxford: Blackwell.

Yamaguchi, Haruhiko. 1988. How to pull strings with words. Deceptive violations in the garden-path joke. Journal of Pragmatics 12: 323-337.

Yus Ramos, Francisco. 1999. Misunderstandings and explicit/implicit communication. Pragmatics 9(4): 487-517.

Yus Ramos, Francisco. 2000. On reaching the intended ironic interpretation. International Journal of Communication 10(1-2): 27-78.

Yus Ramos, Francisco. 2003. Humour and the search for relevance. Journal of Pragmatics 35: 1295-1331.

Yus Ramos, Francisco. 2008. A relevance-theoretic classification of jokes. Lodz Papers in Pragmatics 4(1): 131-157.

Yus Ramos, Francisco. 2012. Relevance Theory and contextual sourcescentred analysis of irony. Current research and compatibility. Paper presented at the $5^{\text {th }}$ International Symposium on Intercultural, Cognitive and Social Pragmatics (EPICS V). Seville: Pablo de Olavide University. 
Yus Ramos, Francisco. Forthcoming a. An inference-centred analysis of jokes: the Intersecting Circles Model of humorous communication.

Yus Ramos, Francisco. Forthcoming b. Relevance Theory and contextual sources-centred analysis of irony: current research and compatibility. 